\title{
Homodynamic Effects of Nesdonal and Propofol in Patients Under Electroconvulsive Therapy
}

\author{
Afsoun Seddighi, Amir Nikouei, Amir Saied Seddighi* \\ Shohada Tajrish Comprehensive Neurosurgical Center of Excellence, Functional Neurosurgery Research Center, Shohada \\ Tajrish Hospital, Shahid Beheshti University of Medical Sciences, Tehran, Iran
}

\begin{abstract}
Background: General anesthesia is a safe method for induction of electroconvulsive therapy (ECT) in patients suffering from psychiatric disorders. We aimed to compare the hemodynamic effects of Nesdonal and propofol as induction agents for ECT.

Methods: This semi-experimental study was performed on 84 patients with confirmed diagnosis of psychiatric disorders, who underwent ECT at Shohada Tajrish hospital in 2016. After randomization, each patient either received Nesdonal or propofol for induction of anesthesia. Hemodynamic changes of mentioned anesthetic agents were recorded and evaluated during ECT, including systolic and diastolic blood pressure, heart rate, seizure duration related to the procedure and recovery from sleep. Statistical analysis was performed using Student $t$ test and Friedman test.

Results: There were 50 men and 34 women among included patients. The mean and standard deviation (SD) of age of patients in Nesdonal group in female and male were $40.5 \pm 13.4$ years and $30.2 \pm 13.5$ years, respectively. Data for propofol group was $36.5 \pm 20.9$ years and $25.7 \pm 7.7$ years for female and male patients, respectively. Nesdonal offered a superior hemodynamic stability during the procedure, and seizure duration has decreased with Nesdonal compared with propofol. However, patients who underwent propofol for their anesthesia recover faster from sleep, while systolic and diastolic blood pressure of this group were higher than Nesdonal group $(P<0.0001)$. Conclusion: Considering better hemodynamic stability, it seems that Nesdonal is better than propofol for induction in ECT.

Keywords: Electroconvulsive therapy; Anesthesia, Nesdonal; Propofol
\end{abstract}

*Correspondence to Amir Saied Seddighi, MD; Functional Neurosurgery Research Center of Shohada Tajrish Hospital, Shahid Beheshti University of Medical Sciences.

Tel: +98(912)21551591; Email: a_sedighi@sbmu.ac.ir

Published online October 8 , 2017

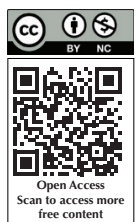

Citation: Seddighi A, Nikouei A, Seddighi AS. Homodynamic effects of Nesdonal and propofol in patients under electroconvulsive therapy. Int Clin Neurosci J. 2017;4(4):140-142. doi: 10.15171/icnj.2017.04.

\section{Introduction}

The brain electroconvulsive therapy (ECT) which is used as a treatment in psychiatry, is one of the most effective, safe and reliable methods in psychiatric disorders. ${ }^{1}$ According to increasing number of ECT procedures performed each year under general anesthesia in the United States, which exceeds the number of coronary revascularization, appendectomy and herniorrhaphy procedures, selecting an appropriate anesthetic agent is mandatory. ${ }^{2}$ ECT stimulates the autonomic nervous system and its most side effects are on the cardiovascular and central nervous system. ${ }^{3}$ It may cause hemodynamic instabilities like myocardial ischemia and infarction, ${ }^{4}$ transient neurologic ischemic deficits and intracerebral hemorrhages. ${ }^{5,6}$ Despite the physiological effects and its frequent use in elderly people with significant co-morbidity, ECT is a low-risk procedure. ${ }^{7}$ The mortality rate of about 1 per 10000 patients (1 per 80000 treatments) is similar to that of anesthesia for minor surgical procedures. ${ }^{8}$ Therefore, administering a drug which has the less hemodynamic changes, and most effective ECT and the less recovery period, is one of the goals in anesthesia.

There are few studies about detailed hemodynamic effects and duration of seizure and apnea along with recovery time of Nesdonal and propofol in patients undergoing ECT. We aimed to compare the hemodynamic effects of Nesdonal and propofol as induction agent for ECT.

\section{Materials and Methods}

This study has been done with filling questionnaire for 84 patients who needed to have ECT, in Shohada Tajrish hospital from January 2016 to December 2016. Before the induction of anesthesia, class of anesthesia was determined based on American Society of Anesthesiologists (ASA), and also gender and age data were collected. Patients who fulfilled inclusion criteria were selected and patients with a history of cardiovascular disease, cerebrovascular

(C) 2017 The Author(s). This is an open-access article distributed under the terms of the Creative Commons Attribution-NonCommercial 4.0 International License (http://creativecommons.org/licenses/by-nc/4.0/) which permits copy and redistribute the material just in noncommercial usages, provided the original work is properly cited. 
disease, pulmonary disease, intracranial hypertension and patients who refuse to sign the informed consent were excluded. Patients were ready to perform ECT by fasting under blood pressure, pulse rate and electrocardiography monitoring. Blood pressure and pulse rate monitoring was performed before and after induction of anesthesia with atropine $(0.5 \mathrm{mg} / \mathrm{kg})$ and esculin $(0.5 \mathrm{mg} / \mathrm{kg})$ and either propofol (1 mg/kg) or Nesdonal (2 mg/kg); also, in 3rd and 10th minute, while patients were in recovery period by eye opening in response to verbal stimulus, mentioned values were recorded. Duration between anesthesia induction and recovery period was also recorded.

\section{Results}

We evaluated 50 men and 34 women. The mean age of the men who received the Nesdonal for induction anesthesia was 30.2 years, and for patients who received propofol was 25.7 years. The age of the women who received Nesdonal for induction anesthesia was 40.5 years and who received propofol was 36.5 years. Forty-one patients received Nesdonal for induction anesthesia and 43 patients received propofol. The mean blood pressure in patients who received Nesdonal before the induction was 103.78 $\mathrm{mm} \mathrm{Hg}$ (systolic)/65.12 mm Hg (diastolic) and in 1st, 3rd and 10th minutes after anesthesia were $127.32 \mathrm{~mm}$ $\mathrm{Hg}$ (systolic)/86.59 mm Hg (diastolic), $150.98 \mathrm{~mm} \mathrm{Hg}$ (systolic)/106.59 mm Hg (diastolic) and $146.59 \mathrm{~mm} \mathrm{Hg}$ (systolic)/101.95 mm Hg (diastolic) respectively. These findings show that the most changes in systolic blood pressure were in the third minutes, where it increased about $45 \%$ and the least changes were in the first minutes with increase range of $22 \%$. The Friedman test, showed a significant relationship between use of Nesdonal and systolic blood pressure $(P<0.001)$. Also most of the changes in diastolic blood pressure occurred in the third minute after anesthesia, where it increased about 64\%, but the least changes have happened in 10th minute and it was about $32 \%$. The Friedman test also showed a significant relationship between use of Nesdonal and changes in diastolic blood pressure $(P<0.001)$. The mean blood pressure in patients who received propofol before the induction was $97.79 \mathrm{~mm} \mathrm{Hg}$ (systolic)/65.00 $\mathrm{mm} \mathrm{Hg}$ (diastolic) and in 1st, 3rd and 10th minutes after anesthesia were $130.47 \mathrm{~mm} \mathrm{Hg}$ (systolic)/89.00 mm Hg (diastolic), $148.37 \mathrm{~mm} \mathrm{Hg}$ (systolic)/106.51 mm Hg (diastolic) and $152.33 \mathrm{~mm} \mathrm{Hg}$ (systolic)/10.6.98 mm Hg (diastolic) respectively. These findings show that the most changes in blood pressure happened in 10th minute with $33 \%$ and $37 \%$ increase in systolic diastolic pressure respectively. The Friedman test showed a significant relationship between use of propofol and changes in systolic and diastolic blood pressure changes $(P<0.001)$. The mean of pulse rate in patients, candidates for Nesdonal, was 85 per minute before the induction, and in 1st, 3rd and 10th minute after anesthesia was 97.4, 107.1 and 98 pulses per minute respectively. These findings show that the most changes in patient's pulse rate were happened in the third minutes after anesthesia with $26 \%$ increase, and the least changes were happened in 10 th minute with $15 \%$ increase. Friedman test showed a significant relationship between Nesdonal usage and pulse change $(P<0.001)$. The mean of pulse rate in patients ready for propofol injection, was 85.9 per minute before the induction, and in 1st, 3rd and 10th minute after anesthesia was 107.5, 113 and 106.6 pulses per minute respectively. Mentioned data shows that the most changes in patient's pulse rate were happened in the third minutes after anesthesia with 33\% increase, and the least changes were happened in 10th minute with $185 \%$ increase. Friedman test showed a significant relationship between propofol utilization and pulse change $(P<0.001)$. The mean of duration of convulsion with Nesdonal was $25.7 \pm 13.4$ seconds, and with propofol

Table 1. Comparison of Mean and Standard Deviation of Blood Pressure, Pulse Rate, Recovery Duration and Apnea Duration of Patients Underwent Either With Propofol or Nesdonal

\begin{tabular}{|c|c|c|c|}
\hline Title & Propofol & Nesdonal & $P$ Value \\
\hline SBP before anesthesia & $97.79 \pm 9.71$ & $103.78 \pm 13.35$ & 0.12 \\
\hline DBP before anesthesia & $65 \pm 7.4$ & $65.12 \pm 8.4$ & 0.14 \\
\hline SBP 1st min & $130.47 \pm 11.93$ & $127.32 \pm 14.49$ & $<0.05$ \\
\hline DBP 1st min & $89.3 \pm 10.99$ & $86.59 \pm 13.43$ & $<0.05$ \\
\hline SBP 3rd min & $148.37 \pm 11.93$ & $150.98 \pm 10.91$ & $<0.05$ \\
\hline DBP $3 r d$ min & $106.51 \pm 10.88$ & $106.59 \pm 11.09$ & $<0.05$ \\
\hline SBP 10th min & $152.33 \pm 16.01$ & $146.59 \pm 13.15$ & $<0.05$ \\
\hline DBP 10th min & $106.98 \pm 11.24$ & $101.95 \pm 13.45$ & $<0.05$ \\
\hline PR before anesthesia & $85.93 \pm 19.23$ & $85.02 \pm 16.91$ & $<0.05$ \\
\hline PR 1st min & $107.47 \pm 21.08$ & $97.44 \pm 18.01$ & $<0.05$ \\
\hline PR 3rd min & $113.98 \pm 25.7$ & $107.1 \pm 28.72$ & $<0.05$ \\
\hline PR 10th min & $106.6 \pm 19.6$ & $98.05 \pm 20.69$ & $<0.05$ \\
\hline Recovery duration (min) & $9.81 \pm 3.64$ & $13.7 \pm 5.1$ & $<0.05$ \\
\hline Apnea duration (s) & $107.74 \pm 50.5$ & $111.52 \pm 46.7$ & 0.08 \\
\hline
\end{tabular}


was $53.3 \pm 28.6$ seconds. Also, the average duration of recovery with Nesdonal was $13.7 \pm 5.1$ minutes, while this value was $9.81 \pm 3.64$ minutes for Propofol group. The Student $t$ test showed a significant relationship between uses of these two drugs with duration of convulsion and duration of recovery $(P<0.05)$. The mean apnea duration in candidates for Nesdonal was $111.52 \pm 46.7$ seconds, and it was $107.74 \pm 50.5$ seconds for propofol group. No significant relationship was observed in post-anesthetic apnea duration between mentioned 2 agents (Table 1).

\section{Discussion}

The effects of ECT are not fully known, but in psychiatric patients who have spontaneous seizure ECT reduces the severity of mental disease. So knowing effects of seizure drugs can be effective in therapeutic process. ECT is mostly used as a treatment for depression with internal origin, and is one the most definitive therapy in depression. ${ }^{9,10}$ Result of a study accomplished on the effect of induction drugs (thiopental and propofol) on the duration of patient's seizure, showed reduced seizure duration following propofol than thiopental. ${ }^{11}$ In another study, propofol and Nesdonal were compared in ECT, and it showed that the decreasing in blood pressure and the duration of convulsion with propofol is less than Nesdonal. ${ }^{12}$ In a study conducted in Geneva, propofol and methohexital were compared and the duration of convulsion during ECT with propofol was shorter than methohexital. ${ }^{13}$ In a study in Agha Khan hospital in Karachi, the effects of propofol and thiopentone sodium on the blood pressure, pulse, duration of seizure and recovery period were compared and the result showed that the cardiovascular stability with propofol was better. ${ }^{14}$ Swartz showed that the duration of convulsion with propofol in ECT is shorter than other agents. ${ }^{15}$ Also in other studies in Morocco, the effects of these two drugs were compared, despite the speed and recovery of propofol were better, ultimately more satisfaction in the use of Nesdonal have been expressed; and it was seen that better anesthesia and better tolerance of patients with Nesdonal can be occurred. ${ }^{16}$ It seems that evaluating therapeutic effects of the drug in order to achieve best therapeutic result with stability in hemodynamic and reducing probable side effects is one of the duties of anesthetics and psychiatric practitioners; and this study is an effort to achieve these goals.

\section{Conclusion}

Based on our findings, Nesdonal offers a more predictable and reliable hemodynamic stability in patients suffering from psychiatric disorders, compared with patients who underwent propofol-induced anesthesia. Also, seizure duration was decreased in patients under Nesdonal anesthetic effect, which is a major deterministic factor in patients who suffer from complicated psychiatric disorders.
Conflict of Interest Disclosures

The authors declare that they have no conflict of interests.

\section{Ethical Statement}

Written informed consent was obtained from the patients with ethical approval of Ethics Committee of Shohada Tajrish hospital based on Declaration of Helsinki 1975.

\section{References}

1. Weiner RD, Falcone G. Electroconvulsive Therapy: How Effective Is It? J Am Psychiatr Nurses Assoc. 2011;17(3):2178. doi: 10.1177/1078390311408603.

2. Thompson JW, Weiner RD, Myers CP. Use of ECT in the United States in 1975, 1980, and 1986. Am J Psychiatry. 1994;151(11):1657-61. doi: 10.1176/ajp.151.11.1657.

3. Ding Z, White PF. Anesthesia for electroconvulsive therapy. Anesth Analg. 2002;94(5):1351-64. doi: 10.1097/00000539200205000-00057.

4. Lopez-Gomez D, Sanchez-Corral MA, Cobo JV, Jara F, Esplugas E. [Myocardial infarction after electroconvulsive therapy]. Rev Esp Cardiol. 1999;52(7):536.

5. Weisberg LA, Elliott D, Mielke D. Intracerebral hemorrhage following electroconvulsive therapy. Neurology. 1991;41(11):1849.

6. Nomoto K, Suzuki T, Serada K, Oe K, Yoshida T, Yamada $S$. Effects of landiolol on hemodynamic response and seizure duration during electroconvulsive therapy. J Anesth. 2006;20(3):183-7. doi: 10.1007/s00540-006-0401-1.

7. Ghaziuddin N, Dumas S, Hodges E. Use of continuation or maintenance electroconvulsive therapy in adolescents with severe treatment-resistant depression. J ect. 2011;27(2):16874. doi: 10.1097/YCT.0b013e3181f665e4.

8. American Psychiatric Association. The practice of electroconvulsive therapy: recommendations for treatment, training, and privileging (A task force report of the American Psychiatric Association). Washington: American Psychiatric; 2008.

9. Dew RE, Kimball JN, Rosenquist PB, McCall WV. Seizure length and clinical outcome in electroconvulsive therapy using methohexital or thiopental. J ect. 2005;21(1):16-8.

10. Seddighi A, Seddighi AS, Nikouei A, Ashrafi F, Nohesara S. Psychological aspects in brain tumor patients: A prospective study. Hell J Nucl Med. 2015;18 Suppl 1:63-7.

11. Bauer J, Hageman I, Dam H, Baez A, Bolwig T, Roed J, et al. Comparison of propofol and thiopental as anesthetic agents for electroconvulsive therapy: a randomized, blinded comparison of seizure duration, stimulus charge, clinical effect, and cognitive side effects. J ect. 2009;25(2):85-90. doi: 10.1097/YCT.0b013e31818a0203.

12. Villalonga A, Bernardo M, Gomar C, Fita G, Escobar R, Pacheco M. Cardiovascular Response and Anesthetic Recovery in Electroconvulsive Therapy with Propofol or Thiopental. Convuls Ther. 1993;9(2):108-11.

13. Walder B, Seeck M, Tramer MR. Propofol [correction of propfol] versus methohexital for electroconvulsive therapy: a meta-analysis. J Neurosurg Anesthesiol. 2001;13(2):93-8.

14. Zaidi NA, Khan FA. Comparison of thiopentone sodium and propofol for electro convulsive therapy (ECT). J Pak Med Assoc. 2000;50(2):60-3.

15. Swartz CM. Propofol Anesthesia in ECT. J ect. 1992;8(4):2626.

16. Harti A, Hmamouchi B, Idali H, Barrou L. [Anesthesia for electroconvulsive therapy: propofol versus thiopental]. Encephale. 2001;27(3):217-21. 